\title{
Particle aggregation at the edges of anticyclonic eddies and implications for distribution of biomass
}

\author{
A. Samuelsen ${ }^{1}$, S. S. Hjøllo ${ }^{2}$, J. A. Johannessen ${ }^{1,3}$, and R. Patel ${ }^{2}$ \\ ${ }^{1}$ Nansen Environmental and Remote Sensing Center, Thormøhlensgate 47, 5006 Bergen, Norway \\ ${ }^{2}$ Institute of Marine Research, Postboks 1870 Nordnes, 5817 Bergen, Norway \\ ${ }^{3}$ Geophysical Institute, University of Bergen, Postboks 7803, 5020, Bergen, Norway
}

Correspondence to: A. Samuelsen (annette.samuelsen@nersc.no)

Received: 2 January 2012 - Published in Ocean Sci. Discuss.: 18 January 2012

Revised: 11 April 2012 - Accepted: 27 April 2012 - Published: 14 June 2012

\begin{abstract}
Acoustic measurements show that the biomass of zooplankton and mesopelagic fish is redistributed by mesoscale variability and that the signal extends over several hundred meters depth. The mechanisms governing this distribution are not well understood, but influences from both physical (i.e. redistribution) and biological processes (i.e. nutrient transport, primary production, active swimming, etc.) are likely. This study examines how hydrodynamic conditions and basic vertical swimming behavior act to distribute biomass in an anticyclonic eddy. Using an eddyresolving $2.3 \mathrm{~km}$-resolution physical ocean model as forcing for a particle-tracking module, particles representing passively floating organisms and organisms with vertical swimming behavior are released within an eddy and monitored for 20 to 30 days. The role of hydrodynamic conditions on the distribution of biomass is discussed in relation to the acoustic measurements. Particles released close to the surface tend, in agreement with the observations, to accumulate around the edge of the eddy, whereas particles released at depth gradually become distributed along the isopycnals. After a month they are displaced several hundreds meters in the vertical with the deepest particles found close to the eddy center and the shallowest close to the edge. There is no evidence of aggregation of particles along the eddy rim in the last simulation. The model results points towards a physical mechanism for aggregation at the surface, however biological processes cannot be ruled out using the current modeling tool.
\end{abstract}

\section{Introduction}

The distribution of chlorophyll and primary production is influenced by mesoscale eddies as is clearly seen in ocean color satellite images, measured in-situ, and demonstrated in models (Benitez-Nelson et al., 2007; Hansen et al., 2010; Frajka-Williams et al., 2009). In the past it was thought that anticyclonic eddies reduced primary productivity by favoring downwelling while cyclonic eddies enhanced primary productivity by upwelling of nutrients (McGillicuddy and Robinson, 1997). More recent studies highlight the importance of sub-mesoscale motion (Klein and Lapeyre, 2009; Mahadevan and Archer, 2000). In addition wind induced Ekman drift-eddy interaction can enhance production in anticyclonic eddies (McGillicuddy et al., 2007). While headway has been made in understanding the influence of mesoscale processes on primary production, our knowledge of how mesoscale eddies affect higher trophic levels, such as zooplankton and fish is still rather limited (Bakun, 2006). One major obstacle is the significant demand to adequately sample the 3-D structure of an eddy with respect to higher trophic levels.

In November 2009 acoustic data was gathered from an anticyclonic eddy showing that large zooplankton and mesopelagic fish also distribute according to the physical structure of the eddy (Godø et al., 2012). In the anticyclonic eddy the biomass of large zooplankton and fish was higher along the edge of the eddy than both inside and outside (Godø et al., 2012). Increased biomass along the eddy rim may be due to the mesoscale and sub-mesoscale activity acting on the nutrient transport, thereby increasing 
phytoplankton productivity, which is then transferred up the food chain resulting in increased biomass of higher trophic levels along the eddy edge. Another reported mechanism is the entrainment of more productive waters from adjacent areas (Sabarros et al., 2009). However, the observation of this phenomenon in the Lofoten Basin (located in the northern part of the Norwegian Sea), in November (as reported by God $\varnothing$ et al., 2012) suggests that other mechanisms may be responsible since the primary production in November at $70^{\circ} \mathrm{N}$ is minimal. Mesoscale and sub-mesoscale activity can also act directly on distribution of food particles, slow- or non-swimming phyto- and zooplankton (Olson et al., 1994; Genin et al., 2005). Hence, if the concentration of food particles increases, this may attract predators like fish and large zooplankton and, in turn, further increase the total biomass concentration.

Deeper in the water column, the acoustic record revealed that the layer of mesopelagic fish was displaced by several hundred meters downwards at the center of the eddy compared to the region outside the eddy (Godø et al., 2012). Some mesopelagic fish exhibit lethargic behavior, probably as a strategy to conserve energy in an environment where food is relatively scarce (Pearcy et al., 1977; Luck and Pietsch, 2008) and may thus also be subject to the hydrodynamic conditions that act in the eddy.

In this paper we investigate the particle aggregation in a mesoscale eddy using a high-resolution 3-dimensional ocean model including a particle-tracking module. The study area is the Lofoten Basin in the northern Norwegian Sea. This area is characterized by northward flowing warm Atlantic water side by side a cold and fresh coastal current. The currents flow along the complex bottom topography, with a steep continental slope separating the coastal margin and deep basins. Mesoscale eddies are common in the area (Andersson et al., 2011; Gascard and Mork, 2008) thus lending itself to a study on mesoscale activity. In Sect. 2 the model and particle simulation experiments are presented, followed by an analyses of the results in Sect. 3. In Sect. 4 the model experiments and results are summarized and discussed in the context of the importance of mesoscale dynamics for biomass distribution and concentration.

\section{Methods}

\subsection{Physical model description}

The HYbrid Coordinate Ocean Model (HYCOM: Bleck, 2002 - www.hycom.org) was set up on a $2.3 \mathrm{~km}$ grid along the coast of mid- and north-Norway (Fig. 1). The model receives nesting conditions from the TOPAZ model of the North Atlantic (Bertino and Lisæter, 2008, http://topaz.nersc. no), which has a resolution of $15 \mathrm{~km}$ in this area. This setup is configured with 28 vertical layers, of which the upper 5 layers are in z-coordinates and the lower 23 layers are hybrid layers, i.e. they are either z-coordinate or isopycnal depending on the water column stratification. The model is forced by the ERA Interim forcing (Simmons et al., 2007), which is a 6-hourly reanalysis product available from 1989 to present. The river forcing is generated using a hydrological model TRIP (Oki and Sud, 1998). Sea surface salinity is relaxed to climatology with a relaxation timescale of 200 days in TOPAZ, while no surface relaxation is applied to the nested model. Tidal forcing is applied at the lateral boundaries of the nested model and is generated from the FES2004 tidal atlas (Lyard et al., 2006).

The model was initialized at the beginning of 1996 with interpolated fields from the larger model (TOPAZ). Because the latter was initiated with GDEM climatology (Carnes, 2009 ) in 1973, we consider a spin-up period of one year for the nested model to be sufficient. The validation of the simulated salinity and temperature fields, predominantly focused on the summer season with satisfactory access to in-situ data, are reported by Samuelsen and Hjøllo (2011). In the open ocean, the modeled salinity and temperature fields compared reasonably well to the time series at station $\mathrm{M}\left(2^{\circ} \mathrm{E}, 66^{\circ} \mathrm{N}\right)$, the main flaw being that the modeled thermocline was too diffuse. This lead to a temperature bias of about $2{ }^{\circ} \mathrm{C}$ and a salinity bias 0.1 in the layer between 600 and $700 \mathrm{~m}$. Above $500 \mathrm{~m}$ and below $1000 \mathrm{~m}$ this bias disappears, and there is little discrepancy between the model and observations. Close to the coast the Norwegian Coastal Current (NCC) had realistic temperatures, but tended to be too saline.

The model includes a particle tracking module, which is an extension of a routine developed for the Miami Isopycnal Ocean Model (Garraffo et al., 2001). For horizontal interpolation of the velocities, a 2-dimensional interpolation on a 16-point grid box surrounding the particle is applied to the instantaneous velocities. The temporal interpolation is performed using a fourth order Runge-Kutta algorithm. The time-step for the particle tracker is $16 \mathrm{~min}$ (4 times the baroclinic time step in the model). The particle tracking routine includes options to let the particles stay at a constant depth, follow isopycnals, or follow the three-dimensional current field. In addition a routine that enables the particles to perform diurnal vertical migration (DVM) (Cushing, 1951; Neilson and Perry, 1990) is implemented. This gives us the opportunity to explore the influence of mesoscale activity on marine organisms with different vertical migration strategies (e.g. Dale and Kaartvedt, 2000) in addition to passively floating organisms and particles.

\subsection{Simulation experiments}

To investigate how isolated eddies affect particle distributions, particles were released in an anticyclonic eddy that was spun off in the northeastern part of the model domain (Fig. 1). This eddy, which was generated during the winter of 1999, travelled slowly ( $\sim 1 \mathrm{~km} /$ day) southwestward over 3 months and became separated from other mesoscale 


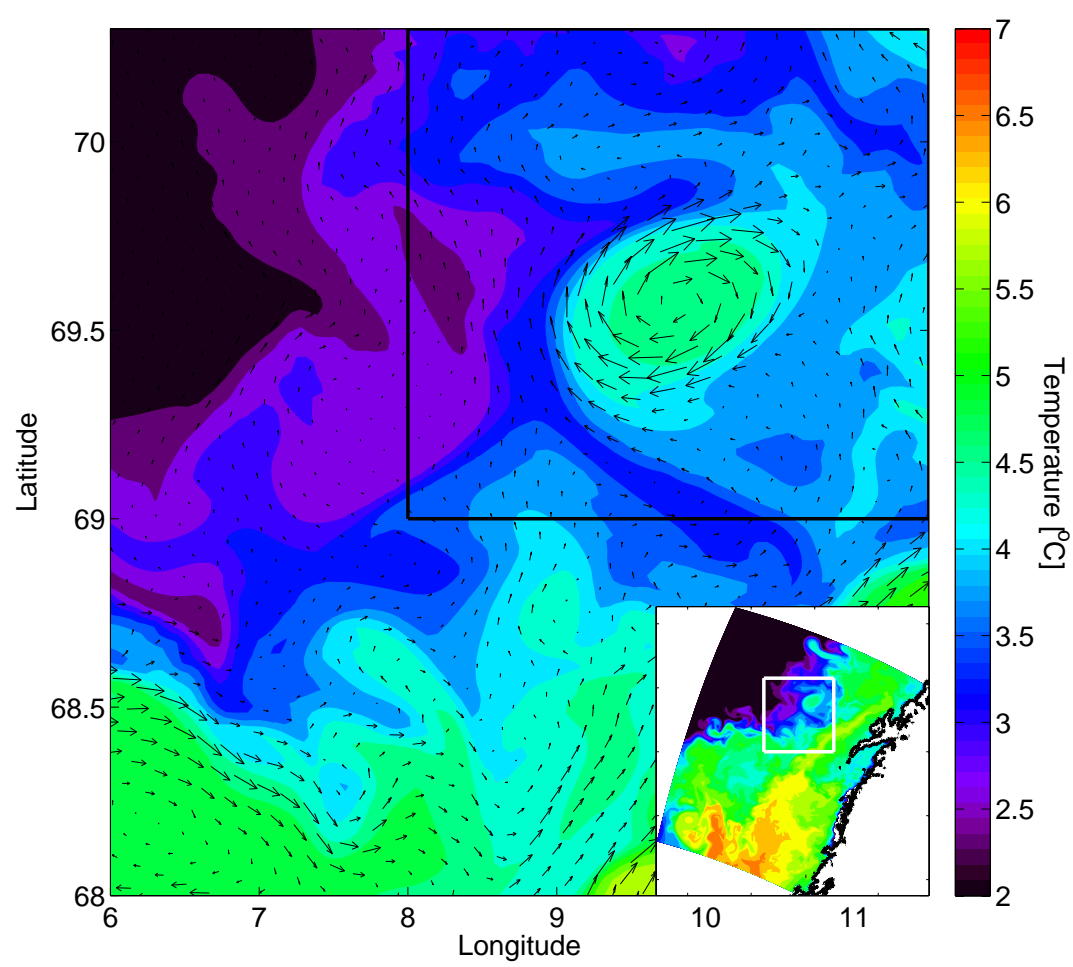

Fig. 1. Surface temperature and currents in the area of the eddy on 21 March 1999, which is the initial day of the particle simulation. The eddy is at this point fairly isolated from other mesoscale activity in the area. The particles at depth were released within the area shown, while the black rectangle indicate the initial area covered by the surface particles. Inserted: The surface temperature of the entire model domain, the white rectangle indicates the area shown in the large figure.

activity. We performed 5 different experiments with released particles, as summarized in Table 1. First, surface particles were released in a square area covering the eddy $\left(8^{\circ} \mathrm{E}-\right.$ $11^{\circ} 30^{\prime} \mathrm{E}$ and $69^{\circ} \mathrm{N}-70^{\circ} 18^{\prime} \mathrm{N}-$ Fig. 1) on March 21 and followed for 20 days. Second, particles at depth were released in a larger area $\left(6^{\circ} \mathrm{E}-11^{\circ} 30^{\prime} \mathrm{E}\right.$, and $68^{\circ} \mathrm{N}-71^{\circ} 18^{\prime} \mathrm{N}-$ Fig. 1) and followed for 30 days. The initial distribution was uniform both in the horizontal and vertical. In the surface experiment 50000 plankton/food particles were released in the upper $100 \mathrm{~m}$ of the eddy while 100000 particles, representing the mesopelagic fish/deep scattering layer, were released between 600 and $800 \mathrm{~m}$. All the particles were released simultaneously on the fist day of the simulations. In the upper water column three experiments were performed: (i) the particles follow the three-dimensional current field; (ii) they are held at a constant depth; and (iii) they perform DVM. The DVM is set to $100 \mathrm{~m}$, which we considered an upper limit for small organisms. The DVM was configured by initiating a downward migration at $6 \mathrm{a} . \mathrm{m}$. and an upward migration at $6 \mathrm{p} . \mathrm{m}$. The particles move with a speed of $20 \mathrm{~m} \mathrm{~h}^{-1}$ and thus use $5 \mathrm{~h}$ to cover the $100 \mathrm{~m}$ migration. The DVM occurs uniformly across the domain. In the deeper layers two experiments were performed; one where the particles were kept at constant depth and the second where they followed the threedimensional current field (Table 1).

\subsection{Physical quantities}

In order to relate the particle distribution from the simulations to the dynamics of the eddy we use the physical quantities vorticity, divergence, vertical velocity and the OkuboWeiss parameter. Vorticity $(\zeta)$ describes the waters tendency to rotate and is expressed mathematically as

$\zeta=\frac{\partial v}{\partial x}-\frac{\partial u}{\partial y}$

Divergence (D) is the tendency of the water to diverge or converge (negative divergence) and is described mathematically

$D=\frac{\partial u}{\partial x}+\frac{\partial v}{\partial y}$

Areas with high divergence or convergence are usually connected areas with high vertical velocity. The vertical velocity from the model is calculated in each layer as the vertical displacement of the layer interfaces, which is the dominant term, in addition to the horizontal advection of layer thickness. 
Table 1. Summarizing the 5 different experiments performed with released particles.

\begin{tabular}{llllll}
\hline $\begin{array}{l}\text { Experiment } \\
\text { name }\end{array}$ & Initial depths & Vertical behavior of the particles & $\begin{array}{l}\text { Number of } \\
\text { particles }\end{array}$ & $\begin{array}{l}\text { Area } \\
\text { length }\end{array}$ \\
\hline P3D & $0-100 \mathrm{~m}$ & Follow the three-dimensional currents & 50000 & small & 20 days \\
PCD & $0-100 \mathrm{~m}$ & Held at the initial depth (constant depth) & 50000 & small & 20 days \\
PVM & $0-50 \mathrm{~m}$ & Perform diurnal migration of $100 \mathrm{~m}$ & 50000 & small & 20 days \\
MCD & $600-800 \mathrm{~m}$ & Held at the initial depth (constant depth) & 100000 & large & 30 days \\
M3D & $600-800 \mathrm{~m}$ & Follow the three-dimensional currents & 100000 & large & 30 days \\
\hline
\end{tabular}
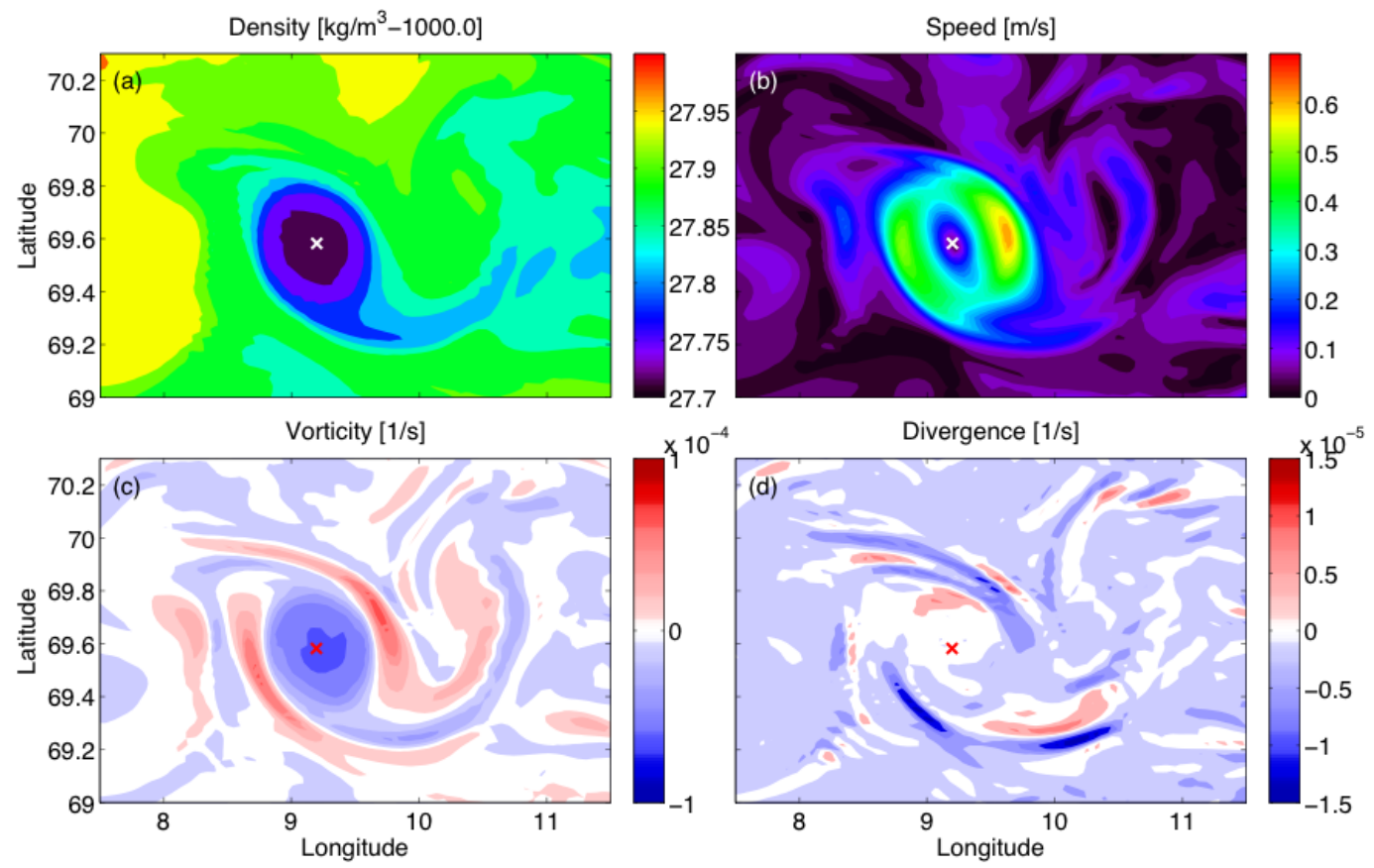

Fig. 2. The physical properties of the eddy. The eddy is almost circular with a small "tail" and, being an anticyclone, has lower density at the center (a). The maximum speed is found around the rim (b), and in the same area the boundary between the core with negative vorticity and the outer part with positive vorticity is found (c). The divergence field (d) is strongest in the outer part of the eddy where there is strong convergence, in addition we find an area with convergence adjacent to an area with divergence in the "tail". All field have been taken from layer 5 (from 16 to $21 \mathrm{~m}$ ) of the model on 31 March 1999. The eddy center has been marked with an "x".

The Okubo-Weiss parameter, W, (Weiss, 1991; Okubo, 1970) is defined as follows:

$W=\underbrace{\left(\frac{\partial u}{\partial x}-\frac{\partial v}{\partial y}\right)^{2}}_{\text {normalstrain }}+\underbrace{\left(\frac{\partial v}{\partial x}+\frac{\partial u}{\partial y}\right)^{2}}_{\text {shearstrain }}-\underbrace{\left(\frac{\partial v}{\partial x}-\frac{\partial u}{\partial y}\right)^{2}}_{\text {vorticity }}$

The Okubo-Weiss parameter is an aid in identifying vorticity-dominant $(W<0)$ and strain-dominated regions $(W>0)$. Very little exchange is expected to occur across the boundary between these two regions. Moreover, intense stirring and exchange processes with the background field may take place in the strain-dominated region (Isern-Fontanet et al., 2004). In the strictest sense the Okubo-Weiss parameter is only applicable to 2-D turbulence, but can also be applied to 3-D fields provided the divergence is moderately weak.

\section{Simulation results}

\subsection{Physical evolution of the eddy}

The anticyclonic eddy was nearly circular and with a radius of $\sim 50 \mathrm{~km}$. It was formed at the frontal boundary between two water masses through a mixture of instability mechanisms. The core water of the eddy had relatively uniform density, while strong density gradients occurred around the edge of the eddy. The eddy had lower density than the surrounding water (Fig. 2) and the strongest currents were found at the edge, particularly in two areas on either side of the eddy center with maximum speed reaching up to $0.64 \mathrm{~m} \mathrm{~s}^{-1}$. These two areas revolved slowly in a clockwise direction as the eddy propagated towards southwest. The eddy had negative vorticity in the middle and bands of positive vorticity 


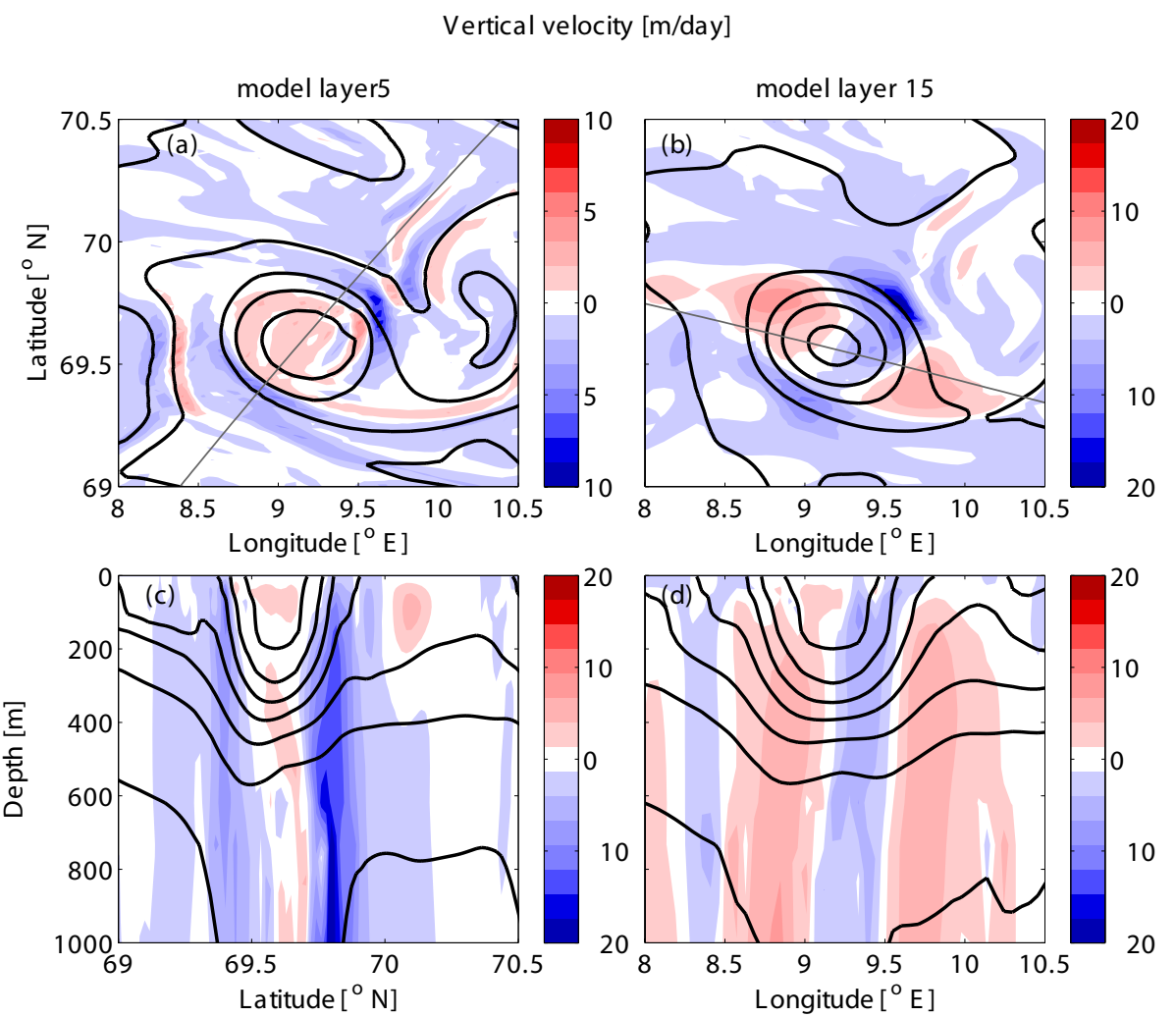

Fig. 3. The vertical velocity in the eddy, close to the surface in layer 5 (16-21 m) (a), and further down in layer 15 (152-178 m) (b). Two cross-sections of the vertical velocity in the eddy are shown (c and $\mathbf{d})$, the location of each cross-section is shown with a gray thin line in the panel above. The thick black lines are isopycnals. The vertical velocity and density are 5-day averages from the period 19-23 March 1999 .

along the edge. The highest vorticity coincided with the two zones of maximum orbital motion.

The divergence pattern, on the other hand, was less distinct, with alternating bands of divergence and convergence in the same area where positive vorticity was found (Fig. 2). The mean divergence over 20 days (not shown) also shows two patches of high convergence on either side of the eddy, and these areas of high convergence stayed fixed in space relative to the eddy. The corresponding vertical velocity in the upper layers of the eddy was upwards in the center and downwards in two bands around the outer rim (Fig. 3). Since these bands revolve with the eddy, the mean vertical velocity over 20 days is uniform around the eddy with upwelling in the eddy center and downwelling along the rim. In particular the regions of downward velocity coincided with regions of strong convergence (Fig. 2). With depth, the vertical velocities increased and alternated between positive and negative velocity on either side of the eddy center. The Okubo-Weiss parameter suggests that the eddy was vorticity dominated in the core and strain dominated in a ring around the core (Fig. 4). The relation between the Okubo-Weiss parameter and particle distribution will be discussed in Sect. 3.2.

The hydrodynamic structure of the eddy gradually weakened throughout the simulation period; e.g. the maximum surface speed decreased from $0.64 \mathrm{~m} \mathrm{~s}^{-1}$ to $0.54 \mathrm{~m} \mathrm{~s}^{-1}$ over 20 days, and the deep isopycnals in the center shoaled, i.e. the $1028.01 \mathrm{~kg} \mathrm{~m}^{-3}$ isopycnal shoaled from $894 \mathrm{~m}$ on March 21 to $851 \mathrm{~m}$ on April 10. During the 20 days the eddy moved roughly $25 \mathrm{~km}$ towards the southwest.

\subsection{Surface particle simulations}

After the particles were released they immediately organized in bands around the rim of the eddy. After only four days the particle concentration had clearly increased in the two patches of high velocity/vorticity on either side of the eddy center described in Sect. 3.1. After a few more days the center of the eddy gradually emptied of particles and the particle concentration increased further at the rim of the eddy, also outside the high-vorticity patches (an animation of particle concentration from the P3D-run is provided as supplementary material). The highest particle concentration coincided with the vorticity patterns, but not the divergence-field as one may have expected (Fig. 4). The spatial de-correlation probably occurs because the areas of strong convergence stay fixed in space relative to the eddy, while the particles are advected with the currents. The patches of high particle concentration were also associated with areas of overall downward velocity (Fig. 3). The highest concentration occurred 

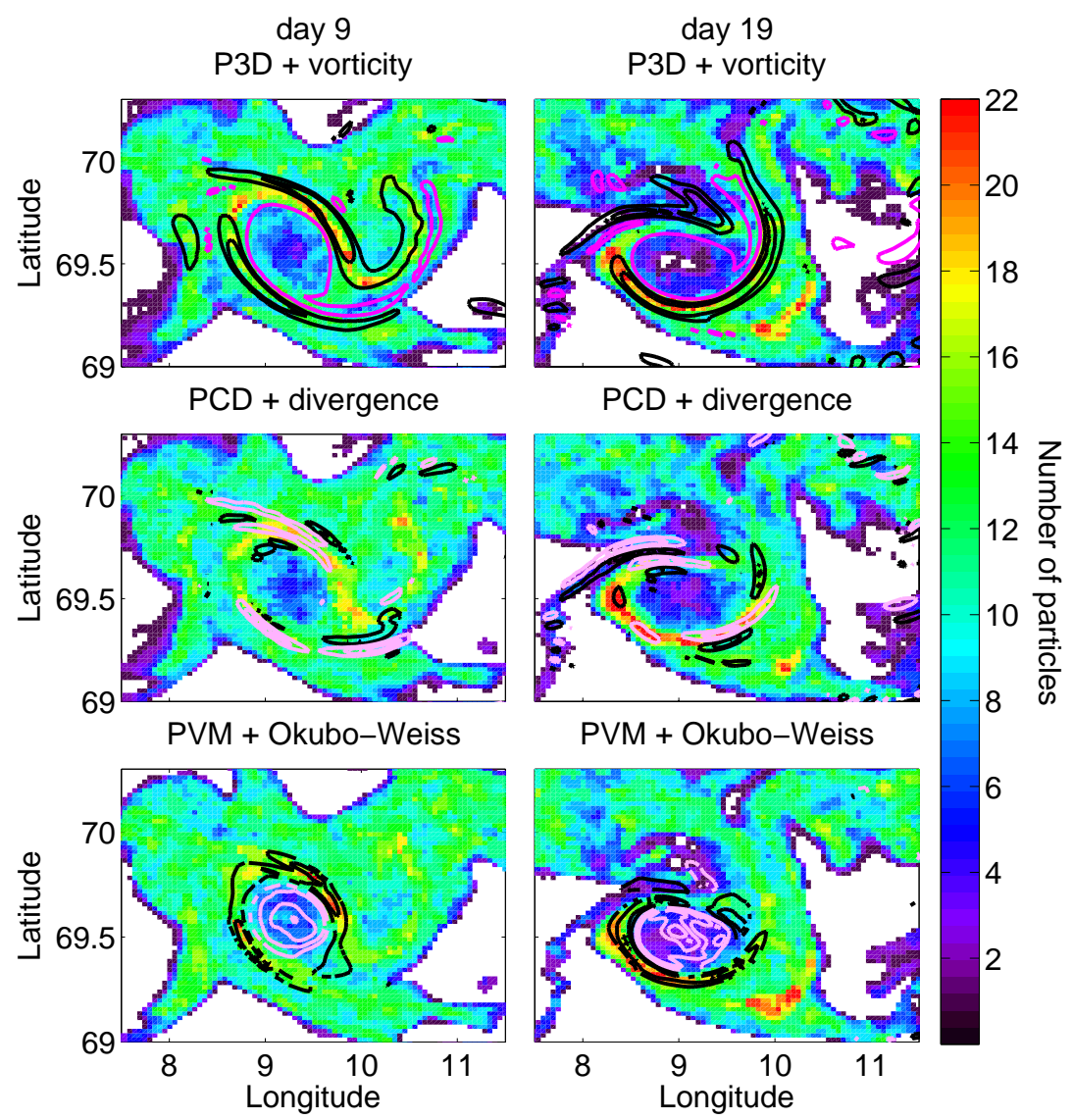

Fig. 4. Depth-integrated particle concentration for each of the surface particle simulations on day 9 (1st column) and day 19 (2nd column) after initialization. The colour show the number of particles within a pixel, white pixels have no particles (the raw fields were filtered with a $3 \times 3$ median filter to make patterns more visible). Particles at all depth were taken into account and the size of the pixels are $1 / 48^{\circ} \times 1 / 19.2^{\circ}$. The overall pattern of distribution is similar for all three runs. Super-imposed on the particle concentrations are physical parameters in model layer 5 plotted as contours - black for positive values and pink for negative values: Upper panel - vorticity (contour intervals: $2 \times 10^{-5} \mathrm{~s}^{-1}$ ), middle panel - divergence (contour intervals: $5 \times 10^{-6} \mathrm{~s}^{-1}$ ), and lower panel - the Okubo-Weiss parameter (contour intervals: $1 \times 10^{-9} \mathrm{~s}^{-2}$ ).

in areas with positive Okubo-Weiss parameter (i.e. strain dominated regions), but there is not a one-to-one correspondence between positive Okubo-Weiss and high particle concentration (Fig. 4).

The particle aggregation along the eddy rim occurred in all three simulations, but the highest particle concentrations were reached in the run with constant depth in the water column (PCD). In the P3D-run the particles were also transported downward along the rim of the eddy. This downward movement was confined to the two bands on either side of the eddy center collocated with the maximum orbital motion and vorticity. Moreover, in all the three runs the upper and inner part of the eddy was gradually emptied for particles. Towards the end of the simulation period the particles were largely absent to the south of the eddy, while they were still abundant to the north because the mean current in the area was northwards. Around the eddy periphery, however, the highest particle concentrations were found to the southwest of the eddy center immediately adjacent to a region outside the eddy that was completely free of particles (Fig. 3).

In all three simulations another patch of high particle concentration occurred outside the eddy on the southeast side (Fig. 4). These particles originated from a patch originally accumulated at the eddy rim that suddenly separated from the eddy around 10 days into the simulation. Whether this is a result of internal eddy dynamics or some external forcing is unclear, but the local wind field applied as forcing did not reveal anything unusual, such as particularly strong winds, in that period.

Particles that ended up clustered in the high-vorticity region originated from the region outside the eddy (Fig. 5), not from the eddy center. Moreover, most of the aggregated particles did not stay in the cluster, but departed from the eddy (Fig. 5). This implies that the patches of high particle concentration occurring in the high-vorticity regions on day 9 and 19 of the simulation seen in Fig. 4 do not consist of the 


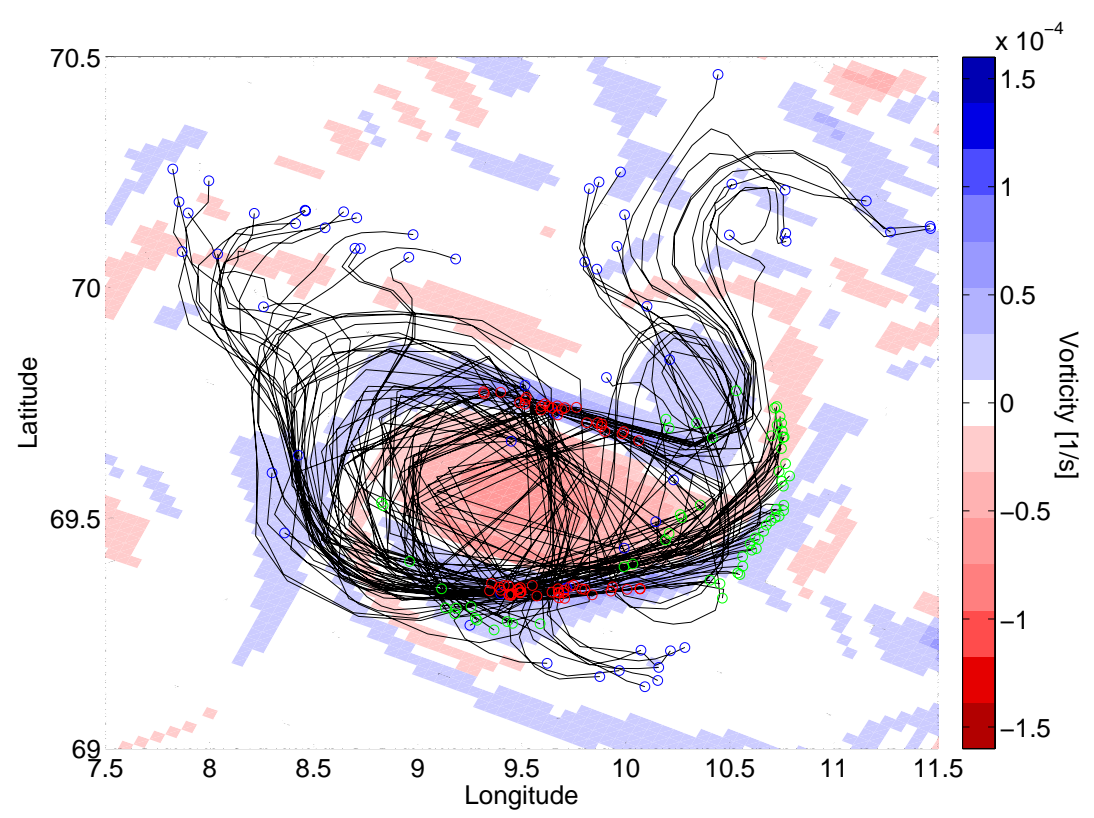

Fig. 5. Surface particle trajectories for a subset the particles that were aggregated in the high-vorticity region after 4 days of simulation. The trajectories are shown on top of the vorticity field on the same day in model layer 5 $(16-21 \mathrm{~m})$. Green circles indicate the initial position, red circles indicate the position on day 4 , and blue circles indicate the final position after 20 days. The straight lines in some of the trajectories occur because the particle positions were only saved every $24 \mathrm{~h}$.

same particles, but that these patches are continuously aggregated as the eddy moves. The particles that originated in the center, on the other hand, tended to stay within the eddy, although the inner ones gradually moved towards the eddy periphery without crossing into the positive vorticity regions. This caused additional increase in the concentration of particles around the eddy rim. In contrast to the particles that ended up in the high-vorticity regions, very few of the particles that originated in the center became detached from the eddy. From a subsample of particles we estimated that $88 \%$ of the particles starting in the eddy center stayed inside the eddy throughout the 20-day simulation. The ones that exited the center did so through the negative-vorticity "tail" seen on Fig. 4 or Fig. 2, reflecting the reluctance of particles to cross vorticity gradients.

\subsection{Particle simulation at depth}

In the simulation with particles between 600 and $800 \mathrm{~m}$ the horizontal distribution stayed fairly uniform as the strongest convergence and divergence occurred close to the surface. In the run with constant vertical distribution there was no difference in the particle concentration in any area in or around the eddy, even after 30 days (Fig. 6). In the run where the particles were allowed to move with the vertical currents, particles were transported vertically, although the depth-integrated horizontal particle distribution stayed fairly constant. After about 10 days particles close to the rim of the eddy had moved 100-200 m both upwards and downwards
(Fig. 6). In accordance with the vertical velocity at depth (Fig. 3), the vertical motion was initially asymmetric with respect to the eddy, but as the eddy revolved the distribution became more symmetric. The particles allowed to move vertically appeared to follow the isopycnals at the rim of the eddy (deepening towards the eddy center), while particles released in the eddy centre moved upwards, creating an empty, bowlshape region at the eddy center between 800 and $1000 \mathrm{~m}$ after 30 days (Fig. 6).

\section{Discussion}

\subsection{Particle dispersion}

A full 3-D high-resolution ocean model with an embedded particle-tracking module has been run in order to investigate the properties of particle aggregation and dispersion with respect to an isolated mesoscale anticyclonic eddy (Fig. 1). An investigation of the physical properties of the eddy revealed that although the density and horizontal speed had near circular isolines around the eddy, this is not the case for the vertical velocity and divergence (Fig. 2 and Fig. 3). Particularly the vertical velocity played a principal part in distributing the particles, and had alternating direction around the eddy circumference (Fig. 3). Several runs, using the same physical forcing, were performed; in the surface layer (upper $100 \mathrm{~m}$ ), the particles had different vertical behavior, some followed the 3-D currents, some were kept at constant depth and only 

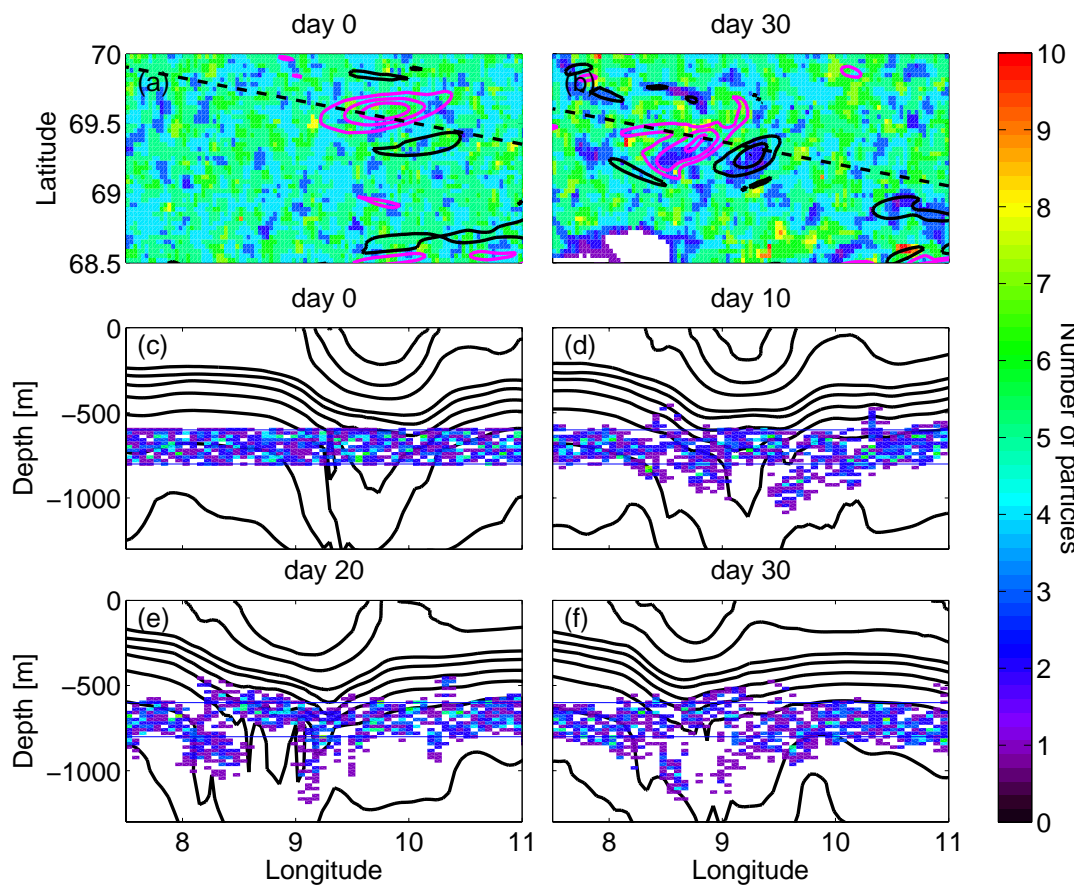

Fig. 6. The two upper panels show depth-integrated horizontal distribution of particles in experiment M3D on (a) day 0 and (b) day 30 . The contours show vorticity in model layer 21 (depth: 437-616 m), contour intervals are $1 \times 10^{-5} \mathrm{~s}^{-1}$ and pink is negative and black positive vorticity. The lower 4 panels show vertical distribution of particles along a section through the middle of the eddy on day (c) 0 (d) 10 , (e) 20 , and (f) 30. All particles in experiment M3D that were within $5 \mathrm{~km}$ of the section were counted and the size of the pixels is $20 \mathrm{~m} \times 2.6 \mathrm{~km}$. The black contour lines in (c)-(f) are isopycnals. Since the eddy moves throughout the simulation, the position of the section followed the eddy, the positions of the section on day 0 and 30 are shown in (a) and (b) respectively.

moved horizontally, and some performed diurnal vertical migration (Table 1). The main result for the surface distribution was largely the same; the eddy center was gradually emptied of particles, while areas around the rim of the eddy attained high concentrations (Fig. 4). The vertical motion of the particles played a lesser role; although the particles that stay at a constant depth attain higher concentrations in terms of particles per volume because they cannot move up or down, the depth-integrated concentration were not significantly different (Fig. 4). Particles released between 600 and $800 \mathrm{~m}$ were either kept at constant depth or followed the 3-D model velocity (Table 1). In contrast to the surface simulations, the depth-integrated number of particles stayed uniform throughout the simulation period, but when the particles were allowed to move vertically (M3D), an evolution where the particles gradually align along the isopycnals was seen. This created an empty area between two layers of particles at the eddy center (Fig. 6). All the particles that ended up in the deepest part of the eddy originated on the western side of the eddy, probably pushed down with the thermocline as the eddy moved southwestward.

At the surface, the highest concentration of particles was associated with high positive vorticity. The particle trajectories revealed that the particles in these high-concentration patches originated outside the eddy (Fig. 5), and, contrary to what we expected in a region where particles appear to aggregate, there was a high exchange of particles between the high-concentration patch and the surrounding area in these regions. The particles originating in the core of the eddy gradually moved outwards during the simulation thus increasing the particle concentration along the eddy rim and gradually emptying the center. Only a few of these particles detached from the eddy during the simulation and only exited through the negative vorticity "tail" of the eddy (Fig. 2), reflecting that the vorticity gradient along the rim of the anticyclonic eddy acts as barrier for the continuous outward spreading of the particles (Priovenzale, 1999). According to Provenzale (1999), regions with positive W (i.e. straindominated regions) have local exponential divergence of nearby particles, while particles in regions with negative $\mathrm{W}$ (vorticity-dominated) stay at the same distance from each other. This agrees with the difference in behavior of the particles in the different regions of the eddy studied here, although Provenzale (1999) considers idealized barotropic flow.

\subsection{Limitations}

The model simulations were executed with realistic atmospheric forcing and boundary conditions, but aimed to discern the physical effects of a generic anticyclonic eddy on 
the the particle distribution and concentration. In so doing an eddy that was fairly isolated from other mesoscale processes was chosen. However, in other realistic simulations it may be possible to find eddies that is almost completely isolated, for instance warm/cold core rings in the Gulf Stream. Although isolated eddies are not uncommon in the ocean, it is more common that they occur in eddy-rich areas, with enhanced likelihood of eddy-eddy interaction. An isolated eddy was chosen here to simplify the analysis, but we expect that the results presented here will aid the analysis of more complete eddy fields in future studies. Ideally it would also be interesting to investigate the effect of a cyclonic eddy on particle distribution, but the eddy field in the model revealed that the cyclonic eddies, although they occurred quite often, are not very stable and tend to be pulled out into elongated filaments after only a few days. This has also been seen in other modeling studies and is a result of weakening of cyclones resulting from strain deformation induced by vortex Rossby waves (Koszalka et al., 2009; Graves et al., 2006).

The vertical velocity (Fig. 3) plays a major role in distributing the particles both at the surface and at depth, but as long as direct observations of the vertical velocities in ocean eddies are rare, the representativeness of the simulated vertical motion remain unknown. The method used for calculating vertical velocity in the model (see Sect. 2.3) avoids the accumulation of errors that can occur when integrating the continuity equation to obtain the vertical velocity.

The number of particles is limited by computational resources, and with 50000-100000 particles over an area of $\mathrm{O}\left(10^{4}\right) \mathrm{km}^{2}$ we come nowhere close to the actual number of non-swimming organisms they are meant to represent. For example, Calanus finmarchius, the dominant copepod of the Norwegian Sea, has typical concentrations of $\mathrm{O}\left(10^{4}-10^{5}\right)$ individuals $/ \mathrm{m}^{2}$ (Samuelsen et al., 2009; Edvardsen et al., 2006). However, experiments with fewer particles showed little difference in the overall results with respect to the horizontal distribution and increasing the number of particles would not make a difference unless we also increase the horizontal resolution of the physical model. For the vertical distribution it is clear that there would be an advantage with more particles, particularly when attempting to represent a section through the eddy (Fig. 6).

Other aspects of "real life" complicate this picture. Most eddies have a temperature difference with the surrounding water and temperature affect the growth of most organism from plankton to fish larvae. A simple numerical exercise (results not shown) showed that if you have a warm eddy in an area with uniform zooplankton concentration, this would lead to increased zooplankton biomass, granted that the zooplankton growth is not food-limited, because of the temperature effect on the growth. If on the other hand the zooplankton biomass is redistributed into high-concentration areas, they may become food limited and this can lead to a reduction in the total biomass. In addition, eddies may increase or decrease the primary production in an area by modifying the vertical nutrient transport to the surface. This would affect the local production and food availability as well. Fish and marine mammal often have preferences for depth, temperature and salinity, and may either avoid or seek the eddy depending on their particular preference. Detritus and fecal pellets can have sinking velocities ranging from 10 to $100 \mathrm{~m} \mathrm{~d}^{-1}$, since this is of the same order of magnitude than the vertical velocities found in the eddy, this may lead to increased concentration of dead particles in the upwelling parts of the eddy. Probably the effect will be largest on slowsinking detritus, since particles with vertical sinking speed of $\sim \mathrm{O}\left(100 \mathrm{~m} \mathrm{~d}^{-1}\right)$ will sink below the eddy in just a few days. The next step in our research will be to investigate these aspect using an individual based model for zooplankton (Hjøllo et al., 2012) rather than simple particles.

\subsection{Model - observation comparison}

The setup of the numerical experiments were originally inspired by the observed distributions of biomass in anticyclonic eddies observed in the field (Fig. 7), the details of these surveys are given in Godø et al. (2012). Specifically an anticyclonic eddy in the Lofoten Basin region in November 2009 showed increased concentration of biomass (specifically krill) at the surface close to the rim of the eddy. At depth, the layer of mesopelagic fish had been displaced several hundred meters downwards (Fig. 7) apparently following the isotherms. The numerical experiment was set up in order to investigate whether the hydrodynamic conditions in the eddy could explain some of these observations of accumulated biomass and whether the vertical positioning of organisms played a role.

The hydrography of the observed eddy revealed that it is fresher and colder than its surroundings and originate from water in the NCC. The modeled eddy is also originating from the NCC and is therefore fresher than its surroundings, but unlike the observed eddy it is also warmer. However since salinity dominates the density effect, their density structure, and therefore the dynamics, is quite similar. Indeed, in the simulations, we do obtain increased concentration of particles close to the surface, in what seems to be narrower bands than those seen in the observations. In addition, modeled particles concentration along the eddy edge was patchy (Fig. 3), so when comparing sections through the eddy from the model, the results will be sensitive to the location of the section. At depth, the model showed a vertical displacement downwards at the center of the eddy of about $300 \mathrm{~m}$. The comparison with data is challenging because a great number of particles are needed to properly represent the particle distribution across a section of the eddy. While the vertical distribution resemble the observation, the acoustic signal in some eddies also show increased concentration of biomass around the eddy rim at depth (Godø et al., 2012), this is not seen in our simulation. 


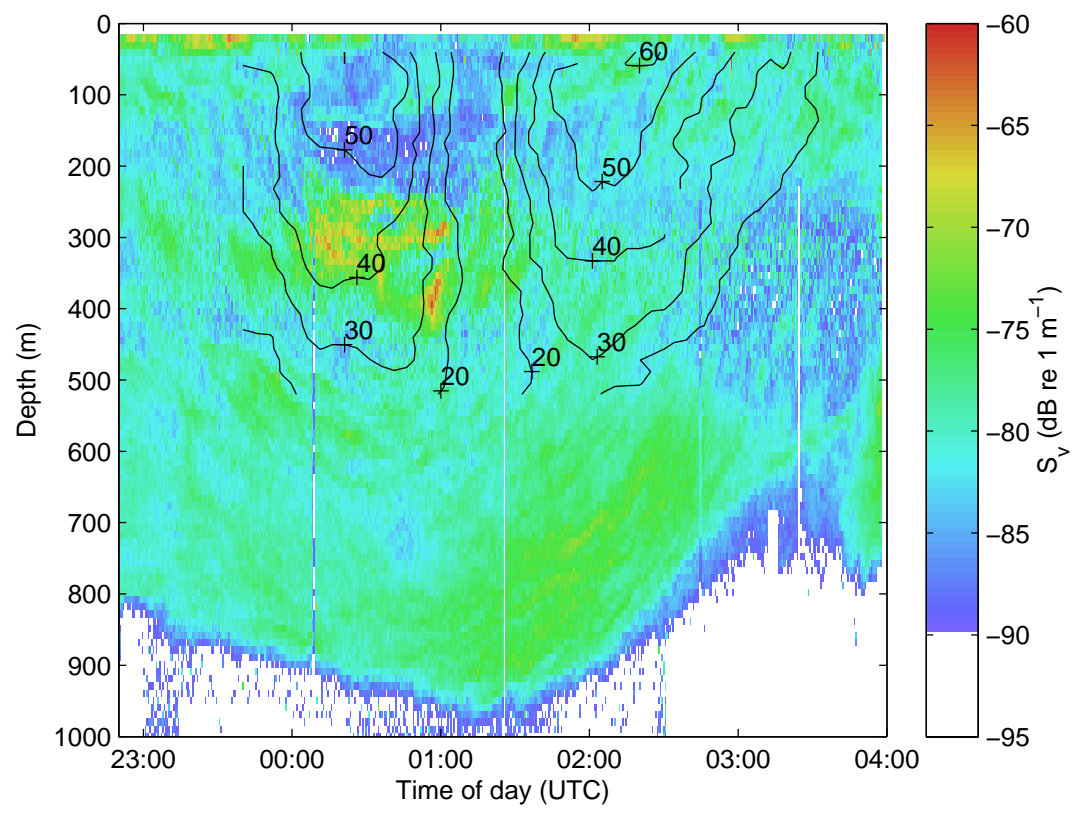

Fig. 7. An example of the acoustic signature of an anticyclone recorded in the Lofoten basin during November 2009 while crossing the eddy from west to east. The edges of the eddy were crossed at about 23:30 and 03:00 and the center between 01:00 and 01:30. The echogram shows mean volume backscattering strength ( $\mathrm{Sv}$, an indication of organism spatial density and hence of biomass). Higher Sv values indicate higher density. Black contour lines show absolute velocity in $\mathrm{cm} \mathrm{s}^{-1}$. Note the higher concentrations of biomass in the surface layer close to the edges ( $<50 \mathrm{~m}$ around 23:30, 02:00, and 03:00) and the empty centre from the surface to $200 \mathrm{~m}$ depth.

The relationship between mesoscale eddies and biomass has also been investigated in other regions. Sabarros et al. (2009) found high concentration of micronekton at the periphery of the eddies, similar to the finding in Godø et al. (2012). While Yebra et al. (2009) and (Holliday et al., 2011) found high biological concentration associated with anticyclonic eddies in the Labrador Sea and off Australia respectively, but no evidence of higher concentration at the eddy rim. The differences could be caused by different eddy dynamics, different stages in the development of the eddy (Bakun, 2006), or differences in the biological organisms present, but more field measurements are necessary to understand the eddy-ecosystem interactions.

Aggregation of particles, as seen in the model simulations, may affect the overall distribution and amount of biomass in relation to mesoscale activity. If we assume that the particles in the simulation represent slow-swimming zooplankton it is conceivable that the high-concentration patches will attract higher trophic levels such as fish and sea birds. One could imagine that swimming fish could just stay in this area and wait for food to come along. On the other hand if the zooplankton are aggregated, their growth may become food limited and after some time the aggregation areas may no longer be attractive to predators. The model showed that there were dynamic differences within regions with high particle concentration. Some regions had a very high exchange of particles and it is not likely that these organisms would experience any food limitation as they are quickly transported away from the area. In other patches there were little exchange with the surroundings and it is more likely that these will experience food shortage, but this of course also depend on the local primary production.

\section{Conclusions}

One objective of this work was to answer the questions as to whether the observed accumulation of biomass along the eddy rim is of physical (hydrodynamic) origin or is associated with biological processes (feeding behavior, increased primary production). The evidence from these numerical experiments points towards the mechanism for aggregation at the surface being of physical origin. But when the organisms have a preferred vertical position in the water column or perform diurnal migration, we see an even greater accumulation. It is possible for other biological processes to either amplify this effect, for example through attracting swimming predators, or damp it, for example by food limitation of the organism that are accumulated, but these processes cannot be inspected with the current modeling tool. As for the distribution at depth, pure hydrodynamics could account for the deepening of the mesopelagic layer at the center of the eddy, but not for the increased biomass at the depth at the eddy's edges. Thus biological processes arise as a potential cause for increased biomass around the eddy periphery at depth. 
Whether this increase in biomass at depth could be connected to the physical accumulation processes at the surface is an open question.

\section{Supplementary material related to this article is available online at: http://www.ocean-sci.net/8/389/2012/ os-8-389-2012-supplement.zip.}

Acknowledgements. This work was supported by the RCN "Havet og Kysten" project AcuSat - 19026I/S40. Many thanks to Gavin John Macaulay for preparing Fig. 7, and to J. Skardhamar, H. Søiland and the two anonymous reviewers for valuable comments on the manuscript. A grant of computer time from the NOTUR Project has also been used.

Edited by: M. Hecht

\section{References}

Andersson, M., Orvik, K. A., LaCasce, J. H., Koszalka, I., and Mauritzen, C.: Variability of the Norwegian Atlantic Current and associated eddy field from surface drifters, J. Geophys. Res., 116, C08032, doi:10.1029/2011JC007078, 2011.

Bakun, A.: Fronts and eddies as key structures in the habitat of marine fish larvae: Opportunity, adaptive response and competitive advantage, Sci. Mar., 70, 105-122, 2006.

Benitez-Nelson, C. R., Bidigare, R. R., Dickey, T. D., Landry, M. R., Leonard, C. L., Brown, S. L., Nencioli, F., Rii, Y. M., Maiti, K., Becker, J. W., Bibby, T. S., Black, W., Cai, W. J., Carlson, C. A., Chen, F. Z., Kuwahara, V. S., Mahaffey, C., McAndrew, P. M., Quay, P. D., Rappe, M. S., Selph, K. E., Simmons, M. P., and Yang, E. J.: Mesoscale eddies drive increased silica export in the subtropical Pacific Ocean, Science, 316, 1017-1021, 2007.

Bertino, L. and Lisæter, K. A.: The TOPAZ monitoring and prediction system for the Atlantic and Arctic Oceans, Journal of Operational Oceanography, 1, 15-18, 2008.

Bleck, R.: An oceanic general circulation model framed in hybrid isopycnic-cartesian coordinates, Ocean Model., 4, 55-88, 2002.

Carnes, M. R.: Description and evaluation of GDEM-V 3.0 Stennis Space Center, Technical report, NRL/MR/7330-09-9165, Stennis, USA, 2009.

Cushing, D. H.: The vertical migration of planktonic crustacea, Biol. Rev., 26, 158-192, 1951.

Dale, T. and Kaartvedt, S.: Diel patterns in stage-specific vertical migration of Calanus finmarchicus in habitats with midnight sun, Ices J. Mar. Sci., 57, 1800-1818, 2000.

Edvardsen, A., Pedersen, J. M., Slagstad, D., Semenova, T., and Timonin, A.: Distribution of overwintering Calanus in the North Norwegian Sea, Ocean Sci., 2, 87-96, doi:10.5194/os-2-872006, 2006.

Frajka-Williams, E., Rhines, P. B., and Eriksen, C. C.: Physical controls and mesoscale variability in the Labrador Sea spring phytoplankton bloom observed by seaglider, Deep-Sea Res. Pt. I, 56, 2144-2161, 2009.
Garraffo, Z. D., Mariano, A. J., Griffa, A., Veneziani, C., and Chassignet, E. P.: Lagrangian data in a high-resolution numerical simulation of the North Atlantic I. Comparison with in situ drifter data, J. Mar. Syst., 29, 157-176, 2001.

Gascard, J.-C. and Mork, K. A.: Climatic Importance of large-scale and mesoscale circulation in the Lofoten Basin Deduced from Lagrangian observations, in: Arctic-Subarctic Ocean Fluxes, edited by: Dickson, R. R., Meincke, J., and Rhines, P., Springer, Dordrecht, 131-143, 2008.

Genin, A., Jaffe, J. S., Reef, R., Richter, C., and Franks, P. J. S.: Swimming against the flow: A mechanism of zooplankton aggregation, Science, 308, 860-862, 2005.

Godø, O. R., Samuelsen, A., Macaulay, G. J., Patel, R., Hjøllo, S. S. t., Horne, J., Kaartvedt, S., and Johannessen, J. A.: Mesoscale eddies are oases for higher trophic marine life, PLoS ONE, 7, e30161, 2012.

Graves, L. P., McWilliams, J. C., and Montgomery, M. T.: Vortex evolution due to straining: A mechanism for dominance of strong, interior anticyclones, Geophys. Astro. Fluid, 100, 151183, 2006.

Hansen, C., Kvaleberg, E., and Samuelsen, A.: Anticyclonic eddies in the Norwegian Sea; their generation, evolution and impact on primary production, Deep-Sea Res. Pt. I, 57, 1079-1091, 2010.

Hjøllo, S. S., Huse, G., Skogen, M. D., and Melle, W.: Modeling secondary production in the Norwegian Sea with a fully coupled physical/primary production/individual-based Calanus finmarchicus model system, Mar. Biol. Res., 8, 508-526, 2012.

Holliday, D., Beckley, L. E., and Olivar, M. P.: Incorporation of larval fishes into a developing anti-cyclonic eddy of the Leeuwin Current off south-western Australia, J. Plankton Res., 33, 16961708, 2011.

Isern-Fontanet, J., Font, J., Garcia-Ladona, E., Emelianov, M., Millot, C., and Taupier-Letage, I.: Spatial structure of anticyclonic eddies in the Algerian Basin (Mediterranean Sea) analyzed using the Okubo-Weiss parameter, Deep-Sea Res. Pt. I, 51, 3009-3028, doi:10.1016/J.Dsr2.2004.09.013, 2004.

Klein, P. and Lapeyre, G.: The oceanic vertical pump induced by mesoscale and submesoscale turbulence, Ann. Rev. Mar. Sci., 1, 351-375, doi:10.1146/annurev.marine.010908.163704, 2009.

Koszalka, I., Bracco, A., McWilliams, J. C., and Provenzale, A.: Dynamics of wind-forced coherent anticyclones in the open ocean, J. Geophys. Res., 114, C08011, doi:10.1029/2009jc005388, 2009.

Luck, D. G. and Pietsch, T. W.: In-situ observations of a deepsea ceratioid anglerfish of the genus oneirodes (lophiiformes: Oneirodidae), Copeia, 2008, 446-451, doi:10.1643/ce-07-075, 2008.

Lyard, F., Lefevre, F., Letellier, T., and Francis, O.: Modelling the global ocean tides: Modern insights from FES2004, Ocean Dyn., 56, 394-415, doi:10.1007/s10236-006-0086-x, 2006.

Mahadevan, A. and Archer, D.: Modeling the impact of fronts and mesoscale circulation on the nutrient supply and biogeochemistry of the upper ocean, J. Geophys. Res.-Oceans, 105, 12091225, 2000.

McGillicuddy, D. J. and Robinson, A. R.: Eddy-induced nutrient supply and new production in the Sargasso Sea, Deep-Sea Res. Pt. I, 44, 1427-1450, 1997.

McGillicuddy, D. J., Anderson, L. A., Bates, N. R., Bibby, T., Buesseler, K. O., Carlson, C. A., Davis, C. S., Ewart, C., Falkowski, 
P. G., Goldthwait, S. A., Hansell, D. A., Jenkins, W. J., Johnson, R., Kosnyrev, V. K., Ledwell, J. R., Li, Q. P., Siegel, D. A., and Steinberg, D. K.: Eddy/wind interactions stimulate extraordinary mid-ocean plankton blooms, Science, 316, 1021-1026, 2007.

Neilson, J. D. and Perry, R. I.: Diel vertical migrations of marine fishes - an obligate or facultative process, Adv. Mar. Biol., 26, 115-168, 1990.

Oki, T. and Sud, Y. C.: Design of total runoff integrating pathways (TRIP) - a global river channel network, Earth Interact., 2, 1-37, 1998.

Okubo, A.: Horizontal dispersion of floatable particles in the vicinity of velocity singularities such as convergences, Deep-Sea Res., 17, 445-454, 1970.

Olson, D. B., Hitchcock, G. L., Mariano, A. J., Ashjian, C. J., Peng, G., Nero, R. W., and Podesta, G. P.: Life on the edge: Marine life at fronts,, Oceanography, 7, 52-60, 1994.

Pearcy, W. G., Krygier, E. E., and Cutshall, N. H.: Biological transport of zinc-65 into the deep sea, Limnol. Oceanogr., 22, 846855, 1977.

Provenzale, A.: Transport by coherent barotropic vortices, Annu. Rev. Fluid Mech., 31, 55-93, doi:10.1146/annurev.fluid.31.1.55, 1999.
Ménard, F., Lévénez, J. J., Tew-Kai, E., and Ternon, J. F.: Mesoscale eddies influence distribution and aggregation patterns of micronekton in the Mozambique Channel, Mar. Ecol. Prog. Ser., 395, 101-107, 2009.

Samuelsen, A. and Hjøllo, S. S.: Physical model development and validation in the acusat project, Nansen Environmental and Remote Sensing Center, Bergen, 2011.

Samuelsen, A., Huse, G., and Hansen, C.: Shelf recruitment of Calanus finmarchicus off the west coast of norway: Role of physical processes and timing of diapause termination, Mar. Ecol. Prog. Ser., 386, 163-180, doi:10.3354/meps08060, 2009.

Simmons, A. S., Uppala, D. D., and Kobayashi, S.: ERA-interim: New ECMWF reanalysis products from 1989 onwards, in: Newsletter, ECMWF, Newsletter 110 - Winter 2006/2007, 11 pp., 2007.

Weiss, J.: The dynamics of enstrophy transfer in two-dimensional hydrodynamics, Physica D: Nonlinear Phenomena, 48, 273-294, 1991.

Yebra, L., Harris, R. P., Head, E. J. H., Yashayaev, I., Harris, L. R., and Hirst, A. G.: Mesoscale physical variability affects zooplankton production in the Labrador Sea, Deep-Sea Res. Pt. I, 56, 703-715, 2009. 